Толеуов Нурлан, старший преподаватель E-mail: nurlantoleuov@gmail.com ORCID ID: 0000-0003-1182-6812

Касенбаева Зарина, старший преподаватель E-mail: kasenbaevaz@bk.ru ORCID ID: 0000-0002-6707-4595

Казахский университет путей сообщения г. Алматы, Республика Казахстан

\title{
ПРЕОБРАЗОВАНИЕ ГРУЗОПОТОКОВ НА ТЕРМИНАЛЬНО-ЛОГИСТИЧЕСКИХ КОМПЛЕКСАХ КАК ЧАСТЬ ЛОГИСТИЧЕСКОЙ ЦЕПИ ДОСТАВКИ ГРУЗОВ
}

Toleuov Nurlan, senior lecturer

E-mail: nurlantoleuov@ gmail.com ORCID ID: 0000-0003-1182-6812

Kasenbaeva Zarina, senior lecturer E-mail: kasenbaevaz@bk.ru ORCID ID:0000-0002-6707-4595 Kazakh university ways of communications Almaty, the Republic of Kazakhstan

\section{TRANSFORMATION OF CARGO FLOWS AT TERMINAL AND LOGISTICS COMPLEXES AS PART OF THE LOGISTICS CHAIN OF CARGO DELIVERY}

Annotation: This article describes the main ways to solve problems, developed a classification of indicators of freight traffic, which allowed to determine the list of indicators that affect the process of loading containers, securing cargo in them and information support.

The article analyzes the operational technology, which includes PRR, fastening of cargo in containers, selection of technological documentation for the transfer of cargo from road to rail, which allowed to determine the subject of research to solve the problems set in the article.

Keywords: cargo flow, container, cargo, loading, transport

Аннотация: В данной статье изложены основные способы решении задач, разработана классификачия показателей грузопотока, что позволила определить перечень показателей, который влияют на процесс загрузки контейнеров, крепления груза в них и информационного сопровождения.

Проанализирована пооперационная технология, включающая в себя ПРР, крепление груза в контейнерах, подбор технологической документачии для передачи грузопотока с автомобильного на железнодорожный транспорт, что позволило определить предмет исследования для решения поставленных в статье задач.

Ключевые слова: грузопоток, контейнер, груз, погрузка, транспорт.

Грузопоток можно определить как процесс направленного перемещения партий груза из одного пункта в другой в различные моменты времени.

Грузопоток характеризуется различными параметрами транспортных партий грузов, от которых в значительной мере зависит технология и организация перегрузочного процесса, транспортировки и складирования грузов.

При планировании и организации эффективного грузопотока важное значение имеет правильный выбор тары, упаковки, параметров грузовых транспортных единиц, размеров транспортных партий, а также организационное, информационное, юридическое и финансовое обеспечение грузопотока. В связи с этим под преобразованием грузопотоков понимается изменение ряда их параметров при передаче грузов с одного транспорта на другой.

Преобразование грузопотоков
Материалы Международной практической интернет-конференции «АктуальныеПроблемыНауки» 
Преобразование параметров грузопотоков для наиболее эффективной дальнейшей доставки грузов, а при необходимости также временное хранение, как правило, происходит на ТЛК. [1]

В результате переработки грузов на ТЛК, в зависимости от его типа и назначения, могут меняться, оцениваться и прогнозироваться показатели грузопотоков. На основе анализа показателей грузопотоков предлагается следующая их классификация (рисунок 1.). Все показатели грузопотока разделяются на пять групп: стоимостные, характеризующие груз, временные, сохранности груза и технологические.

\begin{tabular}{|c|c|c|c|c|}
\hline Стоимостные & 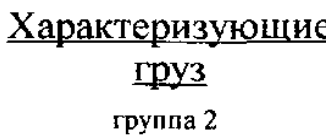 & Временные & $\frac{\text { Сохранности }}{\text { груза }}$ & Технологические \\
\hline $\begin{array}{l}\text { выбор способа } \\
\text { перевозки }\end{array}$ & $\begin{array}{l}\text { общее количество } \\
\text { перемещаемых } \\
\text { грузов за год }\end{array}$ & $\begin{array}{l}\text { время прнбытия илlи } \\
\text { отнравения транспортных } \\
\text { партий грузов }\end{array}$ & сохранность груза & \begin{tabular}{|l|} 
трудоемкость \\
перегрузки груза
\end{tabular} \\
\hline \begin{tabular}{|l|} 
стоимость \\
транспортных \\
партий грузов \\
\end{tabular} & $\begin{array}{l}\text { грузов за год } \\
\text { размер транспортной } \\
\text { партин груза }\end{array}$ & $\begin{array}{l}\text { партий грузов } \\
\text { Іинтервалы времени между } \\
\text { прибытием (отправлением) }\end{array}$ & \begin{tabular}{|l} 
сохранность \\
упаковки, \\
маркировки груза
\end{tabular} & $\begin{array}{l}\text { трудоемкость } \\
\text { сортировки груза }\end{array}$ \\
\hline $\begin{array}{l}\text { расстояние } \\
\text { перевозки } \\
\text { (провозная плата) }\end{array}$ & $\begin{array}{l}\begin{array}{l}\text { характер и параметры } \\
\text { грузовых } \\
\text { гранспортных единиц }\end{array} \\
\end{array}$ & $\begin{array}{l}\text { Еранспортных партий грузов } \\
\text { средний интсрвал врсмеки } \\
\text { между прибытием }\end{array}$ & $\begin{array}{l}\text { сохранность } \\
\text { транспортного } \\
\text { пакета груза }\end{array}$ & $\begin{array}{l}\text { трудоемкость } \\
\text { подработки груза }\end{array}$ \\
\hline $\begin{array}{l}\text { стонмость } \\
\text { перегрузки груза }\end{array}$ & $\begin{array}{l}и с л о \text { наименований } \\
\text { грузов в } \\
\text { транспортной партии }\end{array}$ & $\begin{array}{l}\text { (отнравлением) } \\
\text { транспортных партий } \\
\text { время преобразования }\end{array}$ & & \\
\hline $\begin{array}{l}\text { стоимость средств } \\
\text { кренления }\end{array}$ & $\begin{array}{l}\text { характер и параметры } \\
\text { транспортной тары и } \\
\text { упаковкя грузов }\end{array}$ & грузолотока & & \\
\hline
\end{tabular}

Рисунок 1. Классификация показателей грузопотока

Как показал анализ, из представленных пяти групп показателей грузопотока, стоимостные и технологические показатели рассматриваются на начальном этапе перевозки, определяя возможность преобразования грузопотока в целом. Третья группа показатели временные касаются решения вопроса возможности применения прямого варианта перегрузки груза. На последнем этапе показатели второй и четвертой групп, влияющие в основном на сохранность груза, включают само преобразование грузопотока.

Для дальнейших исследований применяются показатели второй и четвертой групп, в которых закладывается сохранность груза, контейнера и что в конечном итоге влияет на качество всей логистической цепи доставки груза. Остальные группы характеризуют стоимостные и временные показатели, которые являются определяющими при более глубоком анализе экономических показателей и оптимизации деятельности ТЛК, которые не входят в задачи диссертационного исследования.

Передача грузопотока с одного вида транспорта на другой является одной из наиболее распространенных причин нарушения сроков доставки грузов, в организации доставки при мультимодальных перевозках.

От регулярности процесса погрузки грузов изначально существенно зависит и равномерность (или неравномерность) грузопотоков, которые следует преобразовать для перегрузки на другой вид транспорта. Спланировать прибытие и подачу транспорта, сгладить неравномерность его подхода может определить возможность организации прямой перегрузки груза, привести к уменьшению простоя транспортных средств и ускорению продвижения грузопотоков.

В настоящее время на ТЛК прослеживается тенденция к разработке переналаживаемой технологии погрузочно-разгрузочных работ, при которой появляется возможность перерабатывать грузы, отличающиеся по размерам, упаковке и другим

Преобразование грузопотоков
Материалы Международной практической интернет-конференции «АктуальныеПроблемыНауки» 
характеристикам, как по прямому варианту, так и с промежуточным хранением. Такая технология обеспечит минимальные простои транспортных средств взаимодействующих видов транспорта.

На ТЛК выполняются следующие основные технологические операции с контейнерами и самими грузами: разгрузка и погрузка груженых и порожних контейнеров из автомобильного и железнодорожного транспорта; внутритерминальные перемещения контейнеров из зон хранения контейнеров в зоны погрузочно-разгрузочных работ и обратно; хранение груженых и порожних контейнеров; перегрузка грузов из вагонов, автомобилей в контейнеры и обратно, а также из контейнера в контейнер; крепление грузов; оформление перевозочных документов.

Технология погрузочно-разгрузочных работ на ТЛК, их техническое оснащение существенно влияют на общий ритм, организацию и эффективность перевозки грузов и всей работы взаимодействующих видов транспорта. Для обеспечения продвижения грузопотоков ТЛК имеет в своем составе контейнерные площадки, крытые склады, открытые складские площадки, зоны погрузочно-разгрузочных работ и т. д. Компоновка ТЛК представлена на рисунке 2.

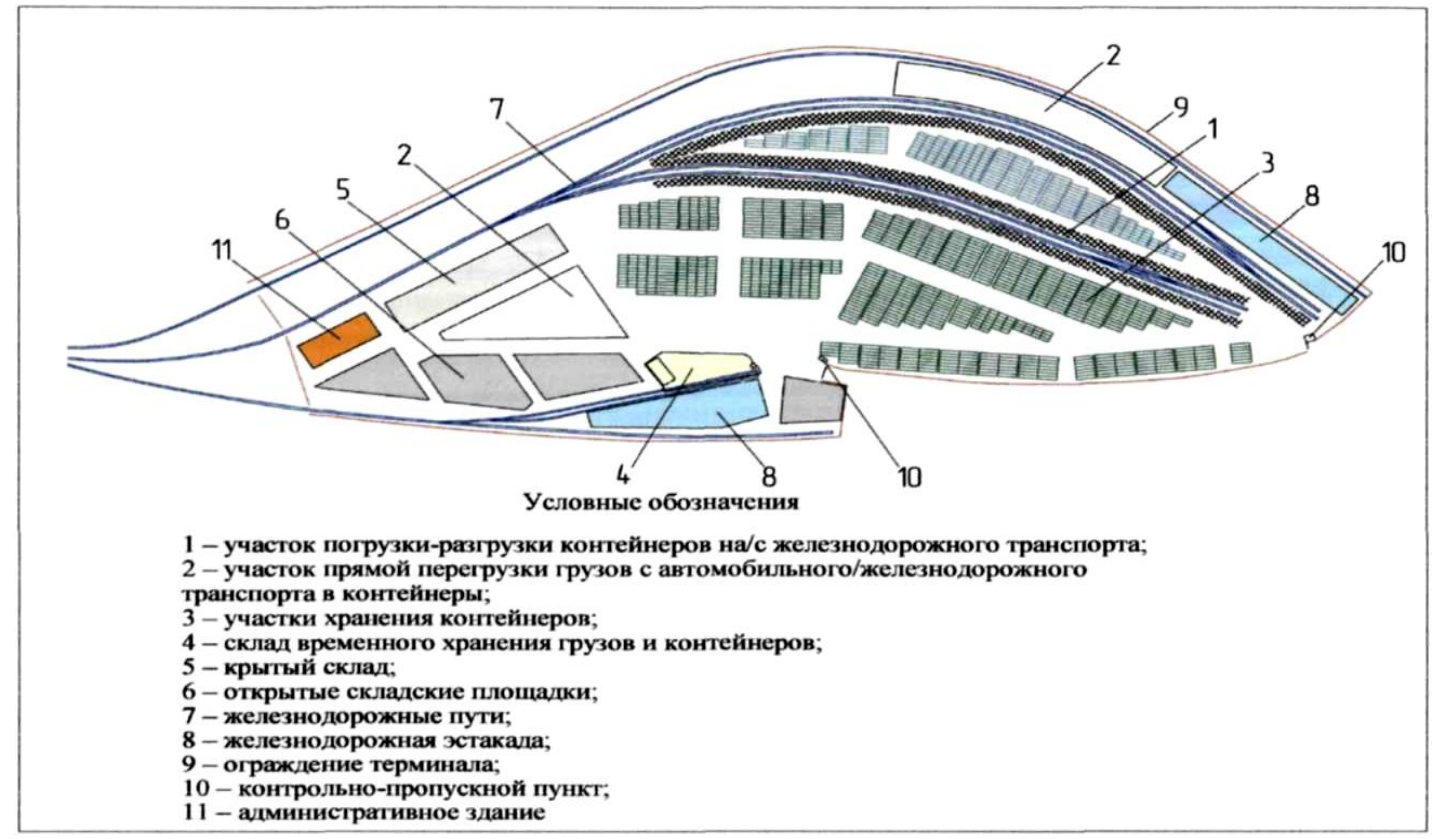

Рисунок 2. Компоновка терминально-логистического комплекса

Простои транспортных средств, общие трудозатраты и себестоимость погрузочноразгрузочных работ, сохранность грузов и подвижного состава также зависят от технологии перегрузочных работ, применяемой на ТЛК.

На ТЛК контейнеры разгружаются (загружаются) с подвижного состава железнодорожного и автомобильного транспорта при помощи грузоподъёмных кранов или автопогрузчиков. Это же оборудование применяют для перестановки контейнеров на участках хранения, загрузки, сортировки и др.

Значимость деятельности, связанной с организацией погрузочно-разгрузочных и складских работ определяется тем, что от времени и качества выполнения погрузочноразгрузочных работ, в определенной мере зависит срок доставки и сохранность груза, конкурентоспособность ТЛК в целом.

Типовые операции, выполняемые на ТЛК, представлены на рисунке 3.

Преобразование грузопотоков
Материалы Международной практической интернет-конференции «АктуальныеПроблемыНауки» 


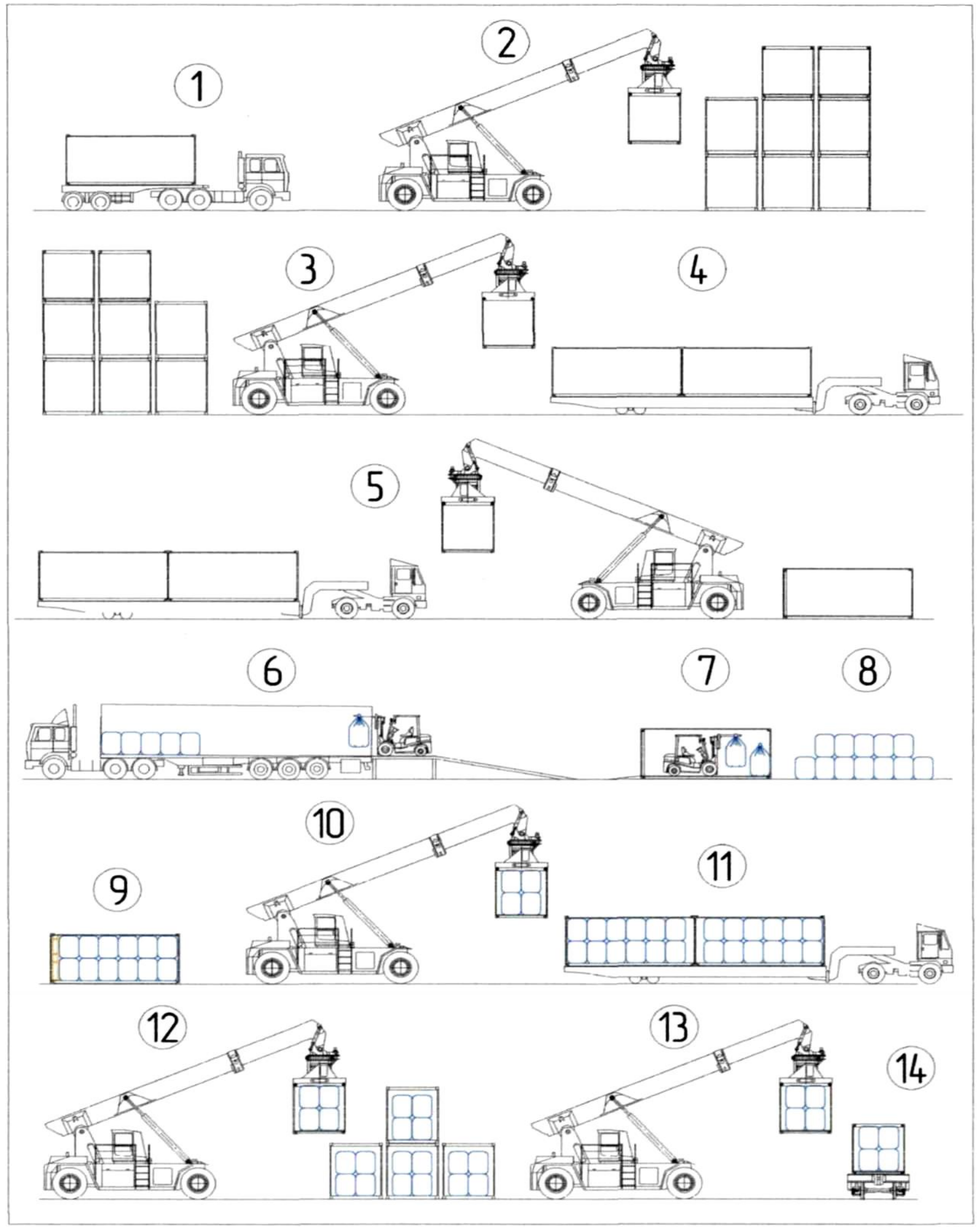

Рисунок 3. Типовые операции, выполняемые на ТЛК

1 - доставка порожнего контейнера на ТЛК автотранспортом; 2 - разгрузка автотранспорта и установка контейнера в штабель ричстакером; 3 - погрузка ролл-трейлера ричстакером;

Материалы Международной практической интернет-конференции «АктуальныеПроблемыНауки» 
4 - доставка контейнера к месту производства погрузочных работ; 5 - разгрузка роллтрейлера; 6 - выгрузка автотранспорта автопогрузчиком; 7 - загрузка контейнера автопогрузчиком; 8 - установка груза в штабель для хранения; 9 - крепление груза в контейнере, документация, сдача контейнера работникам КТЖ; 10 - погрузка контейнера на ролл-трейлер; 11 - доставка контейнера к месту складирования или погрузки; 12 установка контейнера в штабель для хранения; 13 - погрузка контейнера на железнодорожную платформу; 14 - формирование поезда, подготовка документов, отправление.

Операции под номерами 6 - 9 производятся на перегрузочных площадках, где проводятся дальнейшие исследования, включающие разработку рекомендаций по выбору вариантов перегрузки грузов, повышению их сохранности и обеспечению документационного сопровождения [2].

\section{СПИСОК ЛИТЕРАТУРЫ}

1. Крункеева И.А. Существующие логистические цепи и их анализ // XLII Международной научно-практической конференции на тему: «Инновационные технологии на транспорте: образование, наука, практика» в рамках реализации Послания Президента РК Н. Назарбаева «Новые возможности развития в условиях четвертой промышленной революции». - 2018. - 2 том - С. 140-144.

2. Апатцев В.И. и др. Логистические транспортно-грузовые системы: учеб. для студентов высш. учеб. заведений. - М.: Академия, 2003. - 304 с. 